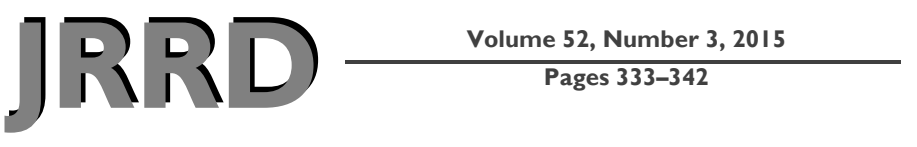

\title{
Performance of a pedometer to measure physical activity in a U.S. cohort with chronic obstructive pulmonary disease
}

\author{
Valery A. Danilack, MPH, PhD; ${ }^{1-2}$ Osarenoma Okunbor, BA; ${ }^{2}$ Caroline R. Richardson, MD; ${ }^{3-4}$ Merilee Teylan, \\ MPH; ${ }^{2}$ Marilyn L. Moy, MD, MSc ${ }^{2,5-6 *}$ \\ ${ }^{1}$ Department of Epidemiology, Brown University School of Public Health, Providence, RI; ${ }^{2}$ Pulmonary and Critical \\ Care Medicine Section, Department of Veterans Affairs (VA) Boston Healthcare System, Boston, MA; ${ }^{3}$ VA Center for \\ Clinical Management Research, Ann Arbor, MI; ${ }^{4}$ Department of Family Medicine, University of Michigan, Ann Arbor, \\ MI; ${ }^{5}$ VA Rehabilitation Research \& Development Service, Washington, DC; ${ }^{6}$ Harvard Medical School, Boston, MA
}

\begin{abstract}
Objective assessment of physical activity (PA) in chronic obstructive pulmonary disease (COPD) is important. We examined the performance of the Omron HJ-720ITC pedometer. A sample of 176 persons with stable COPD wore the Omron and the StepWatch Activity Monitor (SAM) in the clinic and the community. A 4 s step filter in the Omron screens out erroneous intermittent steps; it captures continuous walking that lasts $>4 \mathrm{~s}$. The SAM captures all intermittent and continuous steps walked. Omron-steps were compared with manually counted steps in the clinic and with SAM-steps in the community. We calculated the intraclass correlation coefficient for the first $2 \mathrm{~d}$, the first $3 \mathrm{~d}$, etc., up to $14 \mathrm{~d}$. The Omron registered $>/=90 \%$ of the manually counted steps from the in-clinic walk in 155 of 176 subjects (88\%). In the community, 47 +/$16 \%$ of SAM-steps were continuous ones that were captured by the Omron. For the Omron and the SAM, at least $7 \mathrm{~d}$ of monitoring should be used to capture decreases in PA on weekend days and obtain optimum reliability for all Global Initiative for Chronic Obstructive Lung Disease stages. The Omron accurately and reliably measures continuous walking in COPD. The Omron may be ideal for use in PA interventions that promote continuous walking as exercise.
\end{abstract}

Key words: continuous walking, COPD, exercise, functional capacity, intermittent steps, Omron, pedometer, physical activity, pulmonary disease, StepWatch Activity Monitor.

\section{INTRODUCTION}

Persons with chronic obstructive pulmonary disease (COPD) are significantly less active than healthy persons [1], even at the earliest stages of disease [2-3]. Decreased physical activity (PA), defined as any bodily movement produced by skeletal muscles that results in energy expenditure [4], is associated with increased levels of systemic inflammation and increased risk of hospital admissions, acute exacerbations, and death independent of lung function in persons with COPD [5-10]. Physical inactivity is a major contributor to skeletal muscle dysfunction in COPD [11]. Objective assessment of PA can potentially play a role in risk stratification and development of PA

Abbreviations: COPD = chronic obstructive pulmonary disease, $\mathrm{FEV}_{1}=$ forced expiratory volume in $1 \mathrm{~s}$, GOLD = Global Initiative for Chronic Obstructive Lung Disease, ICC = intraclass correlation coefficient, $\mathrm{PA}=$ physical activity, $\mathrm{SAM}=$ StepWatch Activity Monitor, VA = Department of Veterans Affairs, VMU = vector magnitude unit.

*Address all correspondence to Marilyn L. Moy, MD, MSc; VA Boston Healthcare System, Pulmonary and Critical Care Section, 1400 VFW Pkwy, Mail Code 111PI, West Roxbury, MA 02132; 857-203-6622; fax: 857-203-5670.

Email: marilyn.mov@va.gov

http://dx.doi.org/10.1682/JRRD.2014.11.0282 
interventions $[6-7,12]$. Promoting PA could alter the disease course and improve outcomes in persons with COPD [13].

To date, sophisticated and expensive accelerometers have been used to measure PA in the COPD research setting. They include the Actigraph (Pensacola, Florida); DynaPort (McRoberts; Den Haag, the Netherlands); StepWatch Activity Monitor (SAM) (Orthocare Innovations; Mountlake Terrace, Washington); RT3 (Stayhealthy Inc; Monrovia, California); and SenseWear Armband (BodyMedia Inc; Pittsburgh, Pennsylvania), a multisensor monitor [1,3,5,7,14-18]. They have been shown to be accurate and are able to measure various characteristics of PA such as intensity [19]. However, a limitation of these monitors is that they report different characteristics of PA that are not easily understood by patients if used in the clinical setting. The Actigraph reports activity time and vector magnitude units (VMUs); the Dynaport reports movement intensity and time spent walking, standing, sitting, or lying; the SAM reports step counts; the RT3 reports activity counts and VMUs; and the SenseWear armband reports activity intensity level [5,7,14-18].

There is a need to simplify the devices and the PA characteristic of primary interest if research is to be translated widely to the clinical setting. Commercially available pedometers have gained popularity and may be a simple alternative to accelerometers [20]. Walking, measured by daily step count, is a PA that is relevant to patients, is easy to understand, and potentially can be modified [12,21-23]. Daily step count reflects overall daily PA [24], can be a surrogate for PA level [25], and relates to COPD outcomes of exacerbations and hospitalizations regardless of intensity [7-10]. Of various PA units, steps per day is one of the most sensitive outcomes [26].

Pedometers like the Omron HJ-720ITC (Omron Healthcare Inc; Bannockburn, Illinois) are accurate and user-friendly in the general population and are significantly less expensive than accelerometers [27-30]. A $4 \mathrm{~s}$ step filter is an intrinsic property of the Omron that screens out erroneous steps that might result from shuffling, standing up, sitting down, and vibrations from a moving vehicle [29-30]. Thus, the Omron captures steps from continuous walking that lasts $>4$ s [27-30]. Our pilot work in persons with COPD has shown the Omron pedometer to be accurate in the clinic and feasible for use in an Internet-mediated PA intervention [12,31]. In this study, we extended our work by examining the monitor- ing capabilities of the Omron in COPD. Our aims were to assess (1) the Omron's accuracy in detecting continuous steps in the clinic, (2) the percentage of steps walked in the community that are continuous, (3) the ability of the Omron to detect differences in daily step count observed between weekdays and weekend days [15], and (4) the number of monitoring days needed for optimum reliability.

\section{METHODS}

\section{Study Population}

We studied participants with COPD recruited from the general pulmonary clinics at the Department of Veterans Affairs (VA) Boston Healthcare System from January 2009 through September 2011 and enrolled in an observational research study to characterize daily step count [5-7,21-22]. Eligible participants were over 40 yr of age and had a clinical diagnosis of COPD. Persons who could not ambulate (with or without a walking aid) were excluded. All assessments were conducted with subjects in stable clinical condition when at least 1 mo had elapsed from the time of any treatment for a COPD exacerbation. The protocol was approved by the Institutional Committee on Human Research at the VA Boston Healthcare System, and written informed consent was obtained from all subjects.

\section{Clinical Assessments}

At the in-clinic visit, we assessed demographic characteristics, medical history, and comorbidities. Forced expiratory volume in $1 \mathrm{~s}\left(\mathrm{FEV}_{1}\right)$, measured with an Eaglet spirometer (nSpire Health Inc; Longmont, Colorado), and the 6 min walk test distance were assessed following American Thoracic Society guidelines [32-33]. COPD severity was categorized by Global Initiative for Chronic Obstructive Lung Disease (GOLD) stage, I (mild) to IV (most severe) [34]. Dyspnea at rest was assessed using the modified Medical Research Council scale (responses $0-4$, with 4 being the most dyspneic) [35]. Subjects completed the St. George's Respiratory Questionnaire, with lower total score indicating better health-related quality of life [36].

\section{Physical Activity Monitoring Devices}

The Omron uses a piezoelectric strain gauge to measure acceleration and count steps [29-30]. A 4 s step filter is an intrinsic property of the Omron that screens out 
erroneous steps that might result from shuffling, standing up, sitting down, and vibrations from a moving vehicle [29-30]. Thus, the Omron captures continuous steps that last $>4$ s [27-30]. The Omron is inexpensive (\$32 U.S.), is lightweight (35 g), clips at the waist, and provides feedback with on-instrument digital display of step counts. It interfaces with the Internet via an embedded USB connection, allowing upload of date- and timestamped step counts [27-30].

The SAM, a research-grade device, has no filter and captures all step counts from intermittent lifestyle activities and continuous walking [37-38]. The SAM is a lightweight (38 g) microprocessor-controlled accelerometer designed for persons with mobility limitations [21,3738]. Attached to the ankle with a Velcro strap, the SAM responds to time, acceleration, and position to detect walking motion [21,37-38]. The SAM is highly accurate in persons with chronic diseases, including COPD, but is expensive (\$525 U.S. for device plus $\$ 1,500$ U.S. for docking station and software) and has no on-instrument display [21,37-38]. For this study, the SAM was set at the normal default settings for "walking speed," "range of speeds," and "leg motion," as recommended by the manufacturer [21,37-38].

\section{Step-Count Assessment}

In the clinic, participants walked a predetermined level course of $244 \mathrm{~m}$ at their usual speed while wearing the Omron. Study staff manually counted steps with a tally counter. Omron accuracy was assessed by comparing the Omron-steps with manual steps. Participants were then sent home to wear the Omron and SAM for 14 consecutive days, during all awake hours. Participants were asked to perform their usual PAs, including daily activities and exercise. We covered the digital display on the Omron with a sticker so participants would not receive feedback of step counts. Subjects returned the Omron and SAM by mail, and staff downloaded the date- and timestamped step counts. The percentage of steps walked in the community that represent continuous walking lasting $>4$ s was assessed by comparing Omron-steps (continuous) with SAM-steps (intermittent plus continuous).

\section{Statistical Analysis}

One-hundred seventy-six participants completed the clinic visit and 170 participants completed the home monitoring. Bland-Altman plots compared Omron-steps with manual steps in the clinic and compared Omron- steps to SAM-steps in the community [39]. Valid wear days were defined as ones with $\geq 200$ steps recorded and $\geq 8$ h of wear time $[21,26,31,40]$. For the remaining analyses, we restricted the study population to 128 participants with valid Omron step-count measurements or 136 participants with valid SAM step-count measurements for all $14 \mathrm{~d}$ of monitoring. Changes in step counts, measured by the Omron and SAM, between the first and second week of monitoring and between weekdays and weekend days, overall and stratified by GOLD stage, were assessed using paired $t$-tests. To estimate the reliability of the number of consecutive days monitored, we calculated the intraclass correlation coefficient (ICC) for the first $2 \mathrm{~d}$, the first $3 \mathrm{~d}$, etc., up to and including all $14 \mathrm{~d}$ of stepcount monitoring. The ICC was calculated for the cohort and by GOLD stage using the formula: B/ $\{B+(W / D)\}$, where $B=$ between subject variance, $W=$ within subject variance, and $\mathrm{D}=$ number of days [41].

\section{RESULTS}

Of the subjects, 99 percent were males, with mean \pm standard deviation age $72 \pm 8 \mathrm{yr}$ and $\mathrm{FEV}_{1} 1.55 \pm 0.58 \mathrm{~L}$ (55 $\pm 20 \%$ predicted) [42] (Table 1). Forty-five (26\%) subjects reported regular use of oxygen and 21 (12\%) reported prior participation in pulmonary rehabilitation (Table 1). Twenty-three (13\%) participants reported using a walking aid more than half the time. Eighteen used a cane, one used a walker, two used a cane and a walker, and two used a cane and at times a scooter.

When participants walked the $244 \mathrm{~m}$ course in the clinic, the Omron registered $\geq 90$ percent of the manually counted steps in 155 of the 176 subjects (88\%). It took an average of $4.5 \pm 3.8 \mathrm{~min}$ to perform the step count assessment, with an average stride length of $55.1 \pm 9.2 \mathrm{~cm}$ and walking speed of $3.5 \pm 0.8 \mathrm{~km} / \mathrm{h}$. The Bland-Altman plot displayed a mean difference in step counts (manual minus Omron-steps) of $34 \pm$ 112, 95 percent confidence interval -186 to 253 (Figure 1(a)). Of 2,464 d (176 subjects $\times 14 \mathrm{~d}$ ) monitored in the community, 94 percent had valid Omron step-counts. During the $14 \mathrm{~d}$ monitoring period, on average, $47 \pm 16$ percent of all SAM steps walked by participants were continuous ones that were captured by the Omron. The Bland-Altman plot reveals the presence of a proportional error such that higher daily step counts are associated with increases in the difference in daily step counts (SAM minus Omron-steps) (Figure 1(b)). 
Table 1.

Subject characteristics, $N=176$.

\begin{tabular}{|c|c|}
\hline Characteristic & $\begin{array}{c}\text { Mean } \pm \text { SD } \\
\text { or Frequency (\%) }\end{array}$ \\
\hline Age (yr) & $72 \pm 8$ \\
\hline Stride Length (cm) & $55.1 \pm 9.2$ \\
\hline Walking Speed (km/h) & $3.5 \pm 0.8$ \\
\hline Use of Walking Aid & $23(13)$ \\
\hline Pack Years & $67 \pm 36$ \\
\hline $\begin{array}{l}\text { Prior Participation in Pulmonary } \\
\text { Rehabilitation }\end{array}$ & $21(12)$ \\
\hline Self-Report of Regular Exercise & $60(34)$ \\
\hline Regular Oxygen Use & $45(26)$ \\
\hline Joint Problems & $89(51)$ \\
\hline $\begin{array}{l}\text { Medical Problems Affecting } \\
\text { Walking }\end{array}$ & $94(53)$ \\
\hline Diabetes Mellitus & $46(26)$ \\
\hline Hypertension & $110(62)$ \\
\hline Coronary Artery Disease & $56(32)$ \\
\hline $\mathrm{FEV}_{1}(\mathrm{~L})^{*}$ & $1.55 \pm 0.58$ \\
\hline $\mathrm{FEV}_{1} \%$ Predicted $^{*}$ & $55 \pm 20$ \\
\hline \multicolumn{2}{|l|}{ GOLD Stage ${ }^{*}$} \\
\hline I & $17(10)$ \\
\hline II & $80(46)$ \\
\hline III & $58(33)$ \\
\hline IV & $20(11)$ \\
\hline 6MWT distance (m) & $369 \pm 102$ \\
\hline \multicolumn{2}{|l|}{ mMRC Score } \\
\hline 0 & $8(5)$ \\
\hline 1 & $61(35)$ \\
\hline 2 & $32(18)$ \\
\hline 3 & $47(27)$ \\
\hline 4 & $28(16)$ \\
\hline SGRQ Total Score $^{\dagger}$ & $45 \pm 19$ \\
\hline \multicolumn{2}{|c|}{$\begin{array}{l}{ }^{*} n=175 . \\
{ }^{\dagger} n=174 . \\
6 \mathrm{MWT}=6 \text { min walk test, } \mathrm{FEV}_{1}=\text { forced expiratory volume in } 1 \mathrm{~s} \text {, GOLD = } \\
\text { Global Initiative for Chronic Obstructive Lung Disease, mMRC = modified } \\
\text { Medical Research Council, SD = standard deviation, SGRQ = St. George's } \\
\text { Respiratory Questionnaire. }\end{array}$} \\
\hline
\end{tabular}

We examined in greater detail the 23 persons who used a walking aid. In the clinic, the 23 persons who used a walking aid had an average Omron accuracy compared with manual counts of 83 percent versus 95 percent for the 153 persons who did not use a walking aid. In the clinic, 8 of the 23 (35\%) who used a walking aid had less than 90 percent Omron accuracy versus 14 of the 153 (9\%) who did not use a walking aid. In the community, in the 20 persons who used a walking aid, the Omron detected 40 percent of the steps captured by the SAM versus 47 percent in the 150 persons who did not use a walking aid. Similarly, we more closely characterized the seven persons who had the greatest difference in step counts between manual and Omron-steps (Figure 1(a)). They were generally older, had shorter stride length and lower walking speed, were more likely to use a walking aid, used supplemental oxygen, and self-reported medical problems that affected walking.

Overall, there was no significant difference between daily step counts during the first versus the second week of monitoring by either device (Tables 2 and 3). Participants walked on average 374 more Omron-recorded steps per day on weekdays than weekend days, $p<0.001$. Similarly, persons walked 490 more SAM-recorded steps per day on weekdays than weekend days, $p<0.001$.

Four days of monitoring were needed to achieve an ICC of at least 0.90 for the Omron (Figure 2(a)) and the SAM (Figure 2(b)). Overall, increasing the number of monitoring days from 4 to 9 increased the ICC from 0.90 to 0.95 for the Omron and SAM. The number of monitoring days for optimum reliability differed by GOLD stage, with differences in ICCs between GOLD stages most prominent for the Omron (Figure 2(a)). For the Omron and SAM, participants in GOLD stage I had the highest ICCs and required 3 to $4 \mathrm{~d}$ of monitoring to achieve an ICC $\geq 0.90$. In contrast, participants in GOLD stage IV had the lowest ICCs and required 6 to $7 \mathrm{~d}$ of monitoring to achieve an ICC $\geq 0.90$.

\section{DISCUSSION}

The Omron pedometer can be a simple and inexpensive alternative to accelerometers to monitor PA in persons with COPD. The Omron pedometer is accurate in the majority of persons with COPD when measuring continuous walking in the clinic. Furthermore, 47 percent of all steps taken by persons with COPD in the community are continuous ones that are detected by the Omron. The Omron is reliable, able to capture day-to-day variability in PA level, and able to detect the lower levels of PA during weekend days characteristic of COPD patients [15]. At least seven monitoring days are needed to capture the decreases in PA on weekend days and obtain optimum reliability for all GOLD stages under study.

Understanding the complex interaction between device properties and user characteristics is critical for choosing a device for study. The Omron accurately 
(a)

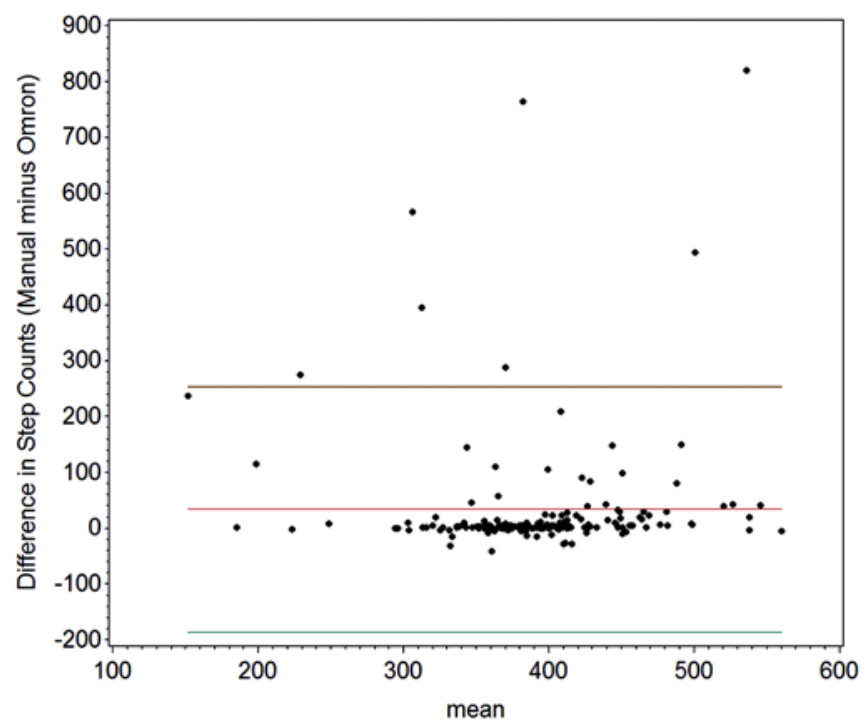

(b)

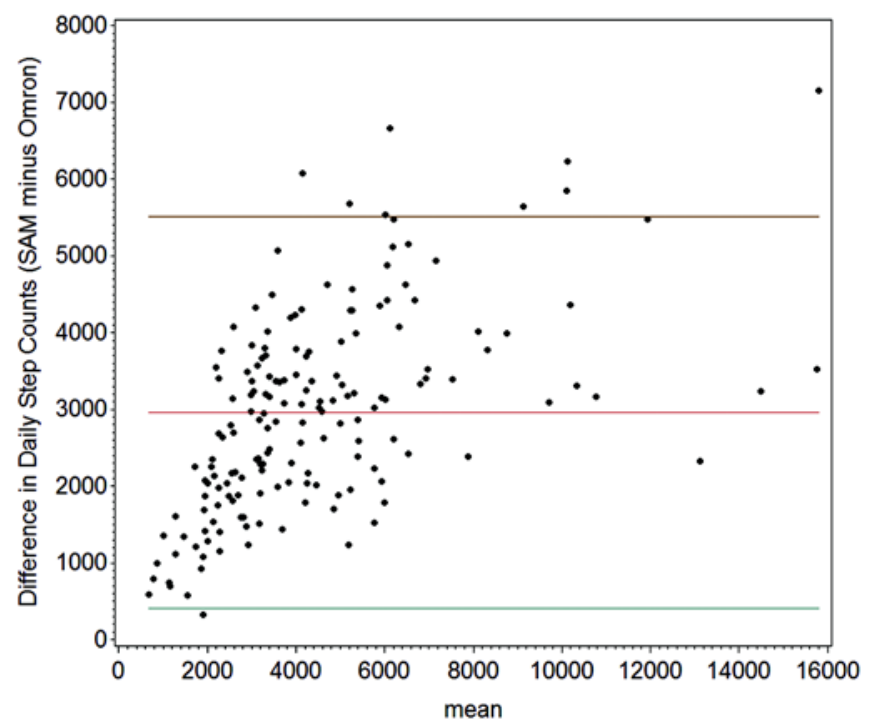

Figure 1.

(a) Bland-Altman plot of manually counted and Omron-measured steps in clinic, $N=176$. (b) Bland-Altman plot of Omron- and StepWatch Activity Monitor (SAM)-measured daily step counts in community, $N=170$.

counts continuous walking that lasts $>4$ s. If a person were to walk $<4 \mathrm{~s}$ and stop, the Omron would not record any steps. Yet human beings commonly walk 4 to 6 steps in a row [43], so the Omron does not capture these intermittent steps. Silcott et al. has similarly shown in normal adults that the Omron records only 52 to 64 percent of SAM step counts in the community and proposed that this is due to the Omron's 4 s filter [30]. Furthermore, we have shown that the Omron has a greater chance of being inaccurate in persons using a walking aid, and the Omron may be less accurate in those who are older, have shorter stride length and lower walking speed, use supplemental oxygen, or have medical problems that affect walking. The choice of monitoring device (accelerometer, pedometer) and PA characteristic (steps, bouts, intensity, moderate-vigorous activity) should ultimately depend on the question asked, characteristics of the COPD population under study, and cost. Based on detailed knowledge about the performance of the Omron, we propose that it can be used as part of interventions to increase PA when the focus is on promoting walking for exercise.

Table 2.

Average daily Omron step count by week and day type, $N=128$.

\begin{tabular}{lccccccc}
\hline & $\boldsymbol{n}$ & $\begin{array}{c}\text { Week 1 } \\
\text { (Days 1-7) }\end{array}$ & $\begin{array}{c}\text { Week 2 } \\
\text { (Days 8-14) }\end{array}$ & $\boldsymbol{p}$-Value & Week Days & Weekend Days & $\boldsymbol{p}$-Value \\
\hline All & 128 & 3,296 & 3,160 & 0.06 & 3,335 & 2,961 & $<0.001$ \\
I & 13 & 4,040 & 3,527 & 0.006 & 3,897 & 3,500 & 0.06 \\
II & 61 & 3,585 & 3,343 & 0.04 & 3,576 & 3,184 & 0.047 \\
III & 40 & 2,909 & 2,947 & 0.71 & 2,996 & 2,758 & 0.09 \\
IV & 13 & 2,210 & 2,230 & 0.87 & 2,348 & 1,900 & 0.05 \\
\hline
\end{tabular}

Note: One participant could not perform spirometry and does not have GOLD stage. GOLD = Global Initiative for Chronic Obstructive Lung Disease. 
JRRD, Volume 52, Number 3, 2015

Table 3.

Average daily StepWatch Activity Monitor step count by week and day type, $N=136$.

\begin{tabular}{lccccccc}
\hline & $\boldsymbol{n}$ & $\begin{array}{c}\text { Week 1 } \\
\text { (Days 1-7) }\end{array}$ & $\begin{array}{c}\text { Week 2 } \\
\text { (Days 8-14) }\end{array}$ & $\boldsymbol{p}$-Value & Week Days & Weekend Days & $\boldsymbol{p}$-Value \\
\hline All & 136 & 5,914 & 5,773 & 0.11 & 5,984 & 5,494 & $<0.001$ \\
I & 14 & 6,794 & 6,347 & 0.03 & 6,726 & 6,181 & 0.17 \\
II & 61 & 6,713 & 6,455 & 0.09 & 6,703 & 6,286 & 0.07 \\
III & 45 & 5,380 & 5,386 & 0.96 & 5,521 & 5,040 \\
IV & 15 & 3,355 & 3,286 & 0.64 & 3,453 & 0.02 & 2,990 \\
\hline
\end{tabular}

Note: One participant could not perform spirometry and does not have GOLD stage.

GOLD = Global Initiative for Chronic Obstructive Lung Disease.

The percentage of steps walked in the community that represent continuous walking is reflected by the fraction of SAM counts captured by the Omron. We concluded that if the Omron accurately captured steps during continuous walking in the clinic, then it would accurately capture these types of steps in the community. In addition, Figure 1(b) shows that higher total daily step counts are associated with increases in the difference between SAM and Omron steps. The most likely reason for this proportional error is that increases predominantly in the number of intermittent steps (detected by the SAM but not the Omron), not continuous steps, contribute to increases in total daily steps.

Overall, persons with COPD have little variability in step counts from day to day regardless of weekend days versus weekdays. The Omron is able to detect the lower

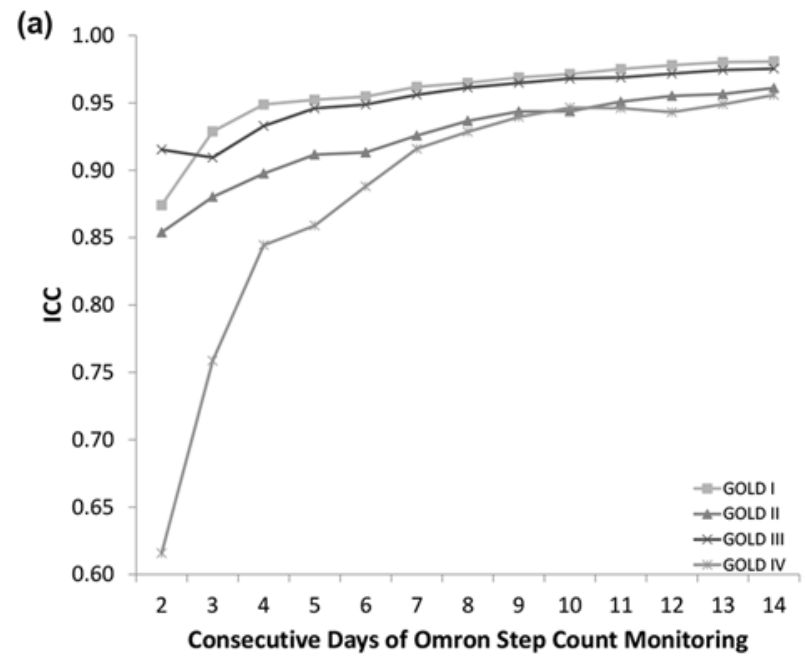

step counts observed on weekend days versus weekdays and is reliable. A $4 \mathrm{~d}$ monitoring period can provide reliable measurements of daily step count, but $7 \mathrm{~d}$ are ideal to capture differences seen on weekend days and between GOLD stages. A previous study examined 17 persons with COPD who had completed pulmonary rehabilitation [37]. Although there was no comparison of weekdays with weekend days, it similarly found that more monitoring days were associated with greater measurement precision. Watz et al. showed that 2 to $3 \mathrm{~d}$ were sufficient for reliable measurement of daily step counts in patients with GOLD stage IV, whereas up to $5 \mathrm{~d}$ of measurement were required in patients with GOLD stage I [41]. The different findings in the two studies may be explained by the facts that the Watz et al. study monitored subjects for $5 \mathrm{~d}$, did not always include weekend days, and used the

Figure 2.

Intraclass correlation coefficients (ICCs) of (a) Omron counts, $N=128$, and (b) StepWatch Activity Monitor (SAM) counts, $N=136$, calculated for the first 2 through $14 \mathrm{~d}$ of monitoring, by Global Initiative for Chronic Obstructive Lung Disease (GOLD) stage. 
SenseWear ProArmband, which underestimates step counts [44].

We significantly extend the literature by fully characterizing the performance of a pedometer in COPD that can be used on a large scale. A PA monitor should be acceptable and user-friendly to the patient [14-15]. Ninety-four percent of days monitored in the community had valid Omron step-counts, demonstrating a high adherence rate for pedometer use. This is in contrast to the 79 to 91 percent compliance previously reported for six PA monitors [16]. The most common problem reported was the Omron falling out of its holder clipped at the waist. To the best of our knowledge, our current study provides the most detailed information about the performance of a pedometer in COPD. Interventions are needed to promote PA in persons with COPD, in whom PA is reduced even at the earliest stages of the disease. Our study in persons with little dyspnea shows that they have reduced daily step counts despite minimal symptoms.

Our study has many strengths, including a large wellcharacterized cohort, a $14 \mathrm{~d}$ monitoring period, and high study adherence. Some limitations deserve discussion. The Omron offers no information on the pattern or intensity of PA, upper-limb activities, or energy expenditure. Studying these characteristics of PA in future studies will be important. Nevertheless, daily step count is a valid surrogate for total PA and does not depend on equations that can be inaccurate for estimation of energy expenditure in COPD [14-16]. There is no gold standard for monitoring step counts in the community; it is not feasible to continuously manually count or videotape steps while participants go about their daily activities. It was reasonable to use the highly accurate SAM to capture all steps in the community. Finally, our study was composed predominantly of male Veterans. Nevertheless, our results provide the rationale to study the use of pedometers in both men and women with COPD.

\section{CONCLUSIONS}

The Omron accurately measures continuous walking in the majority of persons with COPD. Only 47 percent of steps taken by persons with COPD in the community are continuous ones that are detected by the Omron. The Omron is user-friendly, able to detect the lower step counts observed on weekend days versus weekdays, and reliable. At least $7 \mathrm{~d}$ of monitoring should be used to cap- ture decreases in PA on weekend days and obtain optimum reliability for all GOLD stages under study. The Omron may be ideal for use in PA interventions that promote continuous walking as exercise.

\section{ACKNOWLEDGMENTS}

\section{Author Contributions:}

Study concept and design: M. L. Moy.

Acquisition of data: O. Okunbor, M. Teylan.

Analysis and interpretation of data: V. A. Danilack, M. Teylan,

M. L. Moy, C. R. Richardson.

Drafting of manuscript: O. Okunbor, M. L. Moy, C. R. Richardson, V. A. Danilack, M. Teylan.

Critical revision of manuscript for important intellectual content:

O. Okunbor, M. L. Moy, C. R. Richardson, V. A. Danilack, M. Teylan.

Statistical analysis: M. Teylan, V. A. Danilack.

Obtained funding: M. L. Moy.

Administrative, technical, or material support: M. Teylan.

Study supervision: M. L. Moy.

Financial Disclosures: The authors have declared that no competing interests exist.

Funding/Support: This material was based on work supported by the VA, Veterans Health Administration, Rehabilitation Research and Development Service through a VA Career Development Award (F6847W) to Dr. Moy.

Institutional Review: The protocol was approved by the Institutional Committee on Human Research at the VA Boston Healthcare System, and written informed consent was obtained from all subjects.

Participant Follow-Up: The authors plan to notify the study subjects of the publication of this article via a COPD newsletter distributed annually.

Disclaimer: This study was initiated by the investigators. The results of the present study do not constitute endorsement of the Omron or SAM by the authors. Omron Healthcare and Orthocare Innovations had no involvement in the study design; the collection, analysis, and interpretation of data; the writing of the report; or the decision to submit the manuscript for publication.

\section{REFERENCES}

1. Pitta F, Troosters T, Spruit MA, Probst VS, Decramer M, Gosselink R. Characteristics of physical activities in daily life in chronic obstructive pulmonary disease. Am J Respir Crit Care Med. 2005;171(9):972-77. [PMID:15665324] http://dx.doi.org/10.1164/rccm.200407-855OC

2. Van Remoortel H, Hornikx M, Demeyer H, Langer D, Burtin C, Decramer M, Gosselink R, Janssens W, Troosters T. Daily physical activity in subjects with newly diagnosed COPD. Thorax. 2013;68(10):962-63. [PMID:23604460] http://dx.doi.org/10.1136/thoraxjnl-2013-203534 
3. Watz H, Waschki B, Meyer T, Magnussen H. Physical activity in patients with COPD. Eur Respir J. 2009;33(2): 262-72. [PMID:19010994] http://dx.doi.org/10.1183/09031936.00024608

4. Watz H, Pitta F, Rochester CL, Garcia-Aymerich J, ZuWallack R, Troosters T, Vaes AW, Puhan MA, Jehn M, Polkey MI, Vogiatzis I, Clini EM, Toth M, Gimeno-Santos E, Waschki B, Esteban C, Hayot M, Casaburi R, Porszasz J, McAuley E, Singh SJ, Langer D, Wouters EF, Magnussen H, Spruit MA. An official European Respiratory Society statement on physical activity in COPD. Eur Respir J. 2014;44(6):1521-37. [PMID:25359358] http://dx.doi.org/10.1183/09031936.00046814

5. Moy ML, Teylan M, Weston NA, Gagnon DR, Danilack VA, Garshick E. Daily step count is associated with plasma C-reactive protein and IL-6 in a US cohort with COPD. Chest. 2014;145(3):542-50. [PMID:24091482]

http://dx.doi.org/10.1378/chest.13-1052

6. Moy ML, Teylan M, Danilack VA, Gagnon DR, Garshick E. An index of daily step count and systemic inflammation predicts clinical outcomes in chronic obstructive pulmonary disease. Ann Am Thorac Soc. 2014;11(2):149-57. [PMID:24308588] http://dx.doi.org/10.1513/AnnalsATS.201307-243OC

7. Moy ML, Teylan M, Weston NA, Gagnon DR, Garshick E. Daily step count predicts acute exacerbations in a US cohort with COPD. PLoS ONE. 2013;8(4):e60400. [PMID:23593211] http://dx.doi.org/10.1371/journal.pone.0060400

8. Garcia-Aymerich J, Lange P, Benet M, Schnohr P, Antó JM. Regular physical activity reduces hospital admission and mortality in chronic obstructive pulmonary disease: A population based cohort study. Thorax. 2006;61(9):772-78. [PMID:16738033] http://dx.doi.org/10.1136/thx.2006.060145

9. Waschki B, Kirsten A, Holz O, Müller KC, Meyer T, Watz $\mathrm{H}$, Magnussen $\mathrm{H}$. Physical activity is the strongest predictor of all-cause mortality in patients with COPD: A prospective cohort study. Chest. 2011;140(2):331-42. [PMID:21273294] http://dx.doi.org/10.1378/chest.10-2521

10. Esteban C, Arostegui I, Aburto M, Moraza J, Quintana JM, Aizpiri S, Basualdo LV, Capelastegui A. Influence of changes in physical activity on frequency of hospitalization in chronic obstructive pulmonary disease. Respirology. 2014;19(3):330-38. [PMID:24483954]

http://dx.doi.org/10.1111/resp.12239

11. Maltais F, Decramer M, Casaburi R, Barreiro E, Burelle Y, Debigaré R, Dekhuijzen PN, Franssen F, Gayan-Ramirez G, Gea J, Gosker HR, Gosselink R, Hayot M, Hussain SN, Janssens W, Polkey MI, Roca J, Saey D, Schols AM, Spruit MA, Steiner M, Taivassalo T, Troosters T, Vogiatzis I,
Wagner PD; ATS/ERS Ad Hoc Committee on Limb Muscle Dysfunction in COPD. An official American Thoracic Society/European Respiratory Society statement: Update on limb muscle dysfunction in chronic obstructive pulmonary disease. Am J Respir Crit Care Med. 2014;189(9): e15-62. [PMID:24787074]

http://dx.doi.org/10.1164/rccm.201402-0373ST

12. Moy ML, Weston NA, Wilson EJ, Hess ML, Richardson CR. A pilot study of an Internet walking program and pedometer in COPD. Respir Med. 2012;106(9):1342-50. [PMID:22795984] http://dx.doi.org/10.1016/j.rmed.2012.06.013

13. Spruit MA, Singh SJ, Garvey C, ZuWallack R, Nici L, Rochester C, Hill K, Holland AE, Lareau SC, Man WD, Pitta F, Sewell L, Raskin J, Bourbeau J, Crouch R, Franssen FM, Casaburi R, Vercoulen JH, Vogiatzis I, Gosselink R, Clini EM, Effing TW, Maltais F, van der Palen J, Troosters T, Janssen DJ, Collins E, Garcia-Aymerich J, Brooks D, Fahy BF, Puhan MA, Hoogendoorn M, Garrod R, Schols AM, Carlin B, Benzo R, Meek P, Morgan M, Rutten-van Mölken MP, Ries AL, Make B, Goldstein RS, Dowson CA, Brozek JL, Donner CF, Wouters EF; ATS/ ERS Task Force on Pulmonary Rehabilitation. An official American Thoracic Society/European Respiratory Society statement: Key concepts and advances in pulmonary rehabilitation. Am J Respir Crit Care Med. 2013;188(8):e13-64. [PMID:24127811] http://dx.doi.org/10.1164/rccm.201309-1634ST

14. Van Remoortel H, Raste Y, Louvaris Z, Giavedoni S, Burtin C, Langer D, Wilson F, Rabinovich R, Vogiatzis I, Hopkinson NS, Troosters T; PROactive Consortium. Validity of six activity monitors in chronic obstructive pulmonary disease: A comparison with indirect calorimetry. PLOS ONE. 2012;7(6):e39198. [PMID:22745715] http://dx.doi.org/10.1371/journal.pone.0039198

15. Rabinovich RA, Louvaris Z, Raste Y, Langer D, Van Remoortel H, Giavedoni S, Burtin C, Regueiro EM, Vogiatzis I, Hopkinson NS, Polkey MI, Wilson FJ, Macnee W, Westerterp KR, Troosters T; PROactive Consortium. Validity of physical activity monitors during daily life in patients with COPD. Eur Respir J. 2013;42(5):1205-15. [PMID:23397303] http://dx.doi.org/10.1183/09031936.00134312

16. Van Remoortel H, Giavedoni S, Raste Y, Burtin C, Louvaris Z, Gimeno-Santos E, Langer D, Glendenning A, Hopkinson NS, Vogiatzis I, Peterson BT, Wilson F, Mann B, Rabinovich R, Puhan MA, Troosters T; PROactive Consortium. Validity of activity monitors in health and chronic disease: A systematic review. Int J Behav Nutr Phys Act. 2012;9:84. [PMID:22776399] http://dx.doi.org/10.1186/1479-5868-9-84 
17. Hecht A, Ma S, Porszasz J, Casaburi R; COPD Clinical Research Network. Methodology for using long-term accelerometry monitoring to describe daily activity patterns in COPD. COPD. 2009;6(2):121-29.

[PMID:19378225]

http://dx.doi.org/10.1080/15412550902755044

18. Steele BG, Belza B, Cain KC, Coppersmith J, Lakshminarayan S, Howard J, Haselkorn JK. A randomized clinical trial of an activity and exercise adherence intervention in chronic pulmonary disease. Arch Phys Med Rehabil. 2008;89(3):404-12. [PMID:18295615] http://dx.doi.org/10.1016/j.apmr.2007.11.003

19. Donaire-Gonzalez D, Gimeno-Santos E, Balcells E, Rodríguez DA, Farrero E, de Batlle J, Benet M, Ferrer A, Barberà JA, Gea J, Rodriguez-Roisin R, Antó JM, GarciaAymerich J. Physical activity in COPD patients: Patterns and bouts. Eur Respir J. 2013;42(4):993-1002.

[PMID:23258786]

http://dx.doi.org/10.1183/09031936.00101512

20. Tudor-Locke C, Craig CL, Aoyagi Y, Bell RC, Croteau KA, De Bourdeaudhuij I, Ewald B, Gardner AW, Hatano Y, Lutes LD, Matsudo SM, Ramirez-Marrero FA, Rogers LQ, Rowe DA, Schmidt MD, Tully MA, Blair SN. How many steps/day are enough? For older adults and special populations. Int J Behav Nutr Phys Act. 2011;8:80.

[PMID:21798044] http://dx.doi.org/10.1186/1479-5868-8-80

21. Moy ML, Danilack VA, Weston NA, Garshick E. Daily step counts in a US cohort with COPD. Respir Med. 2012;106(7):962-69. [PMID:22521225] http://dx.doi.org/10.1016/j.rmed.2012.03.016

22. Danilack VA, Weston NA, Richardson CR, Mori DL, Moy ML. Reasons persons with COPD do not walk and relationship with daily step count. COPD. 2014;11(3):290-99. [PMID:24152213]

23. Heppner PS, Morgan C, Kaplan RM, Ries AL. Regular walking and long-term maintenance of outcomes after pulmonary rehabilitation. J Cardiopulm Rehabil. 2006;26(1): 44-53. [PMID:16617228] http://dx.doi.org/10.1097/00008483-200601000-00010

24. Walker PP, Burnett A, Flavahan PW, Calverley PM. Lower limb activity and its determinants in COPD. Thorax. 2008; 63(8):683-89. [PMID:18487318]

http://dx.doi.org/10.1136/thx.2007.087130

25. Depew ZS, Novotny PJ, Benzo RP. How many steps are enough to avoid severe physical inactivity in patients with chronic obstructive pulmonary disease? Respirology. 2012; 17(6):1026-27. [PMID:22672739] http://dx.doi.org/10.1111/j.1440-1843.2012.02207.x

26. Demeyer H, Burtin C, Van Remoortel H, Hornikx M, Langer D, Decramer M, Gosselink R, Janssens W, Troosters T. Standardizing the analysis of physical activity in patients with COPD following a pulmonary rehabilitation program. Chest. 2014;146(2):318-27.

http://dx.doi.org/10.1378/chest.13-1968

[PMID:24603844]

27. Holbrook EA, Barreira TV, Kang M. Validity and reliability of Omron pedometers for prescribed and self-paced walking. Med Sci Sports Exerc. 2009;41(3):670-74. [PMID:19204582] http://dx.doi.org/10.1249/MSS.0b013e3181886095

28. Hasson RE, Haller J, Pober DM, Staudenmayer J, Freedson PS. Validity of the Omron HJ-112 pedometer during treadmill walking. Med Sci Sports Exerc. 2009;41(4):805-9. [PMID:19276853] http://dx.doi.org/10.1249/MSS.0b013e31818d9fc2

29. Rider BC, Bassett DR, Thompson DL, Steeves EA, Raynor H. Monitoring capabilities of the Omron HJ-720ITC pedometer. Phys Sportsmed. 2014;42(1):24-29.

[PMID:24565818] http://dx.doi.org/10.3810/psm.2014.02.2044

30. Silcott NA, Bassett DR Jr, Thompson DL, Fitzhugh EC, Steeves JA. Evaluation of the Omron HJ-720ITC pedometer under free-living conditions. Med Sci Sports Exerc. 2011;43(9):1791-97. [PMID:21311356] http://dx.doi.org/10.1249/MSS.0b013e318212888c

31. Moy ML, Janney AW, Nguyen HQ, Matthess KR, Cohen M, Garshick E, Richardson CR. Use of pedometer and Internet-mediated walking program in patients with chronic obstructive pulmonary disease. J Rehabil Res Dev. 2010;47(5):485-96. [PMID:20803392] http://dx.doi.org/10.1682/JRRD.2009.07.0091

32. Miller MR, Hankinson J, Brusasco V, Burgos F, Casaburi R, Coates A, Crapo R, Enright P, van der Grinten CP, Gustafsson P, Jensen R, Johnson DC, MacIntyre N, McKay R, Navajas D, Pedersen OF, Pellegrino R, Viegi G, Wanger J; ATS/ERS Task Force. Standardisation of spirometry. Eur Respir J. 2005;26(2):319-38. [PMID:16055882] http://dx.doi.org/10.1183/09031936.05.00034805

33. ATS Committee on Proficiency Standards for Clinical Pulmonary Function Laboratories. ATS statement: Guidelines for the six-minute walk test. Am J Respir Crit Care Med. 2002;166(1):111-17. [PMID:12091180] http://dx.doi.org/10.1164/ajrccm.166.1.at1102

34. Rabe KF, Hurd S, Anzueto A, Barnes PJ, Buist SA, Calverley P, Fukuchi Y, Jenkins C, Rodriguez-Roisin R, van Weel C, Zielinski J; Global Initiative for Chronic Obstructive Lung Disease. Global strategy for the diagnosis, management, and prevention of chronic obstructive pulmonary disease: GOLD executive summary. Am J Respir Crit Care Med. 2007;176(6):532-55. [PMID:17507545] http://dx.doi.org/10.1164/rccm.200703-456SO 
35. Mahler DA, Wells CK. Evaluation of clinical methods for rating dyspnea. Chest. 1988;93(3):580-86. [PMID:3342669] http://dx.doi.org/10.1378/chest.93.3.580

36. Jones PW, Quirk FH, Baveystock CM, Littlejohns P. A self-complete measure of health status for chronic airflow limitation. The St. George's Respiratory Questionnaire. Am Rev Respir Dis. 1992;145(6):1321-27. [PMID:1595997] http://dx.doi.org/10.1164/ajrccm/145.6.1321

37. Nguyen HQ, Burr RL, Gill DP, Coleman K. Validation of the StepWatch device for measurement of free-living ambulatory activity in patients with chronic obstructive pulmonary disease. J Nurs Meas. 2011;19(2):76-90. [PMID:22003809] http://dx.doi.org/10.1891/1061-3749.19.2.76

38. Cindy Ng LW, Jenkins S, Hill K. Accuracy and responsiveness of the stepwatch activity monitor and ActivPAL in patients with COPD when walking with and without a rollator. Disabil Rehabil. 2012;34(15):1317-22. [PMID:22200080] http://dx.doi.org/10.3109/09638288.2011.641666

39. Bland JM, Altman DG. Statistical methods for assessing agreement between two methods of clinical measurement. Lancet. 1986;1(8476):307-10. [PMID:2868172] http://dx.doi.org/10.1016/S0140-6736(86)90837-8

40. Matthews CE, Hagströmer M, Pober DM, Bowles HR. Best practices for using physical activity monitors in population-based research. Med Sci Sports Exerc. 2012;44(1 Suppl 1):S68-76. [PMID:22157777] http://dx.doi.org/10.1249/MSS.0b013e3182399e5b

41. Watz H, Waschki B, Boehme C, Claussen M, Meyer T, Magnussen H. Extrapulmonary effects of chronic obstructive pulmonary disease on physical activity: A cross-sectional study. Am J Respir Crit Care Med. 2008;177(7):743-51.

\section{[PMID:18048807]}

http://dx.doi.org/10.1164/rccm.200707-10110C

42. Hankinson JL, Odencrantz JR, Fedan KB. Spirometric reference values from a sample of the general U.S. population. Am J Respir Crit Care Med. 1999;159(1):179-87. [PMID:9872837] http://dx.doi.org/10.1164/ajrccm.159.1.9712108

43. Orendurff MS, Schoen JA, Bernatz GC, Segal AD, Klute GK. How humans walk: Bout duration, steps per bout, and rest duration. J Rehabil Res Dev. 2008;45(7):1077-89. [PMID:19165696] http://dx.doi.org/10.1682/JRRD.2007.11.0197

44. Langer D, Gosselink R, Sena R, Burtin C, Decramer M, Troosters T. Validation of two activity monitors in patients with COPD. Thorax. 2009;64(7):641-42. [PMID:19561287] http://dx.doi.org/10.1136/thx.2008.112102

Submitted for publication November 12, 2014. Accepted in revised form February 6, 2015.

This article and any supplementary material should be cited as follows:

Danilack VA, Okunbor O, Richardson CR, Teylan M, Moy ML. Performance of a pedometer to measure physical activity in a U.S. cohort with chronic obstructive pulmonary disease. J Rehabil Res Dev. 2015;52(3):333-42. http://dx.doi.org/10.1682/JRRD.2014.11.0282

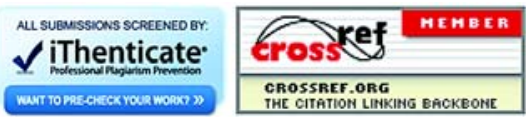

